\title{
Quantitative Analysis of Matrine and Oxymatrine in Sophora flavescens Extract and Its Biopesticides by UPLC
}

\author{
Sung Jin Lim, Du Yun Jeong, Geun Hyoung Choi, Byung Jun Park, Jin Hyo Kim* \\ Chemical Safety Division, National Academy of Agricultural Science, Rural Development Administration, \\ Suwon, Republic of Korea \\ Email: setup75@rda.go.kr
}

Received 5 March 2014; revised 11 April 2014; accepted 19 April 2014

Copyright (C) 2014 by authors and Scientific Research Publishing Inc.

This work is licensed under the Creative Commons Attribution International License (CC BY). http://creativecommons.org/licenses/by/4.0/

c) (i) Open Access

\section{Abstract}

Successive cartridge clean-up method for the simultaneous determination of matrine and oxymatrine in biopesticides containing Sophora flavescens extract was developed and validated by UPLC. The clean-up method was established with ENVI-Carb $(0.5 \mathrm{~g})$ and $\mathrm{C}_{18}$ SPE $(0.5 \mathrm{~g})$ cartridges for the bioactive alkaloid in biopesticides from $S$. flavescens, and the eluate was analyzed to quantify the matrine and oxymatrine by UPLC. The developed method was validated, and the recovery and LOQ of both materials were $105.0 \%$ and $103.6 \%$, and 0.050 and $0.684 \mathrm{mg}^{-1} \mathrm{~kg}^{-1}$, respectively. Of the twenty one samples, the total content of matrines were analyzed by using the developed method and the result showed $<\mathrm{LOQ}-\mathbf{0 . 7 1 \%}$. Therefore, the developed successive clean-up method could contribute to the manufacture and control of biopesticides including matrines, and can be applied to the method development for the analysis of alkaloid materials in biopesticides.

\section{Keywords}

Matrine, Oxymatrine, Biopesticide, Quantitative Analysis

\section{Introduction}

Recently, biopesticide with broad-spectrum to pest control has been actively investigated for its sustainability to avoid disrupting the ecosystem and environmental contamination originated from synthetic alternatives [1]-[4]. Also, the quality control of the commercial biopesticides is one of the big issues to guarantee of efficiency and stability of biopesticides and safety to the environment. The plant extract containing insecticidal and fungicidal substances is a great

${ }^{*}$ Corresponding author.

How to cite this paper: Lim, S.J., et al. (2014) Quantitative Analysis of Matrine and Oxymatrine in Sophora flavescens Extract and Its Biopesticides by UPLC. Journal of Agricultural Chemistry and Environment, 3, 64-73. 
source of the biopesticides due to fewer burdens on human health and sustainable agricultural environment [5] [6].

Sophora flavescens is a traditional Chinese medicinal herb and has been used for anti-tumor, viral hepatitis and anti-arthritis [7]-[9]. Also, various bioactive compounds such as quinolizidine alkaloid, flavonoids, and saponin have been reported in S. flavescens [10]-[15]. Of these major bioactive components, matrine and oxymatrine, which are quinolizidine alkaloids, are known as bioactive materials against various insect pests, pathogenic fungi, bacteria, and nematodes [16]-[20]. Due to this scientific evidence for insecticidal and anti-microbial activity of S. flavescens, currently twenty-one commercial biopesticides from S. flavescens extract have been approved by the Rural Development Administration for use and marketed in Korea. These comercial biopesticides have been generally manufactured by mixing natural extracts, minerals, surfactants, expanders, and solvents. Hence, the composition of each biopesticide would vary depending on the type of pigments, lipids, and surfactants and the contents from extracts and additives.

Many researchers reported different extractions and clean-up methods to achieve the quantification of bioactive materials with tedious and/or repeated chromatography based on the polarity of chemicals [21]-[25]. Although various clean-up procedures and instrumental analysis methods [26]-[32] for matrine and oxymatrine using liquid chromatography (LC), LC-mass spectroscopy (MS), and LC-MS/MS in Chinese medicines, animal tissues, and cell media had been reported, the quantitative analytical method for the content in biopesticides is still unknown. And the quantitative analysis of bioactive compounds in biopesticide can be more complicated than the extract due to some additives [33]. Therefore, the objective of this study was to compare the clean-up efficiency for commercial biopesticides containing $S$. flavescens extract with solid phase extraction (SPE), and to develop an ultra-performance liquid chromatography (UPLC) method for the simultaneous determination of matrine and oxymatrine. Also, we investigated those contents in commercial biopesticide containing $S$. flavescens extract for quality control using the developed method.

\section{Materials and Methods}

\subsection{Chemicals and Reagents}

Matrine (purity 99.9\%) and oxymatrine (purity 94.3\%) were purchased from ChromaDex (Irvine, California, USA). High performance liquid chromatography (HPLC) grade methyl alcohol (MeOH), acetonitrile, and acetone were purchased from Tedia (Ohio, USA). Hydrophilic lipophilic balanced (HLB) SPE (60 mg, $3 \mathrm{~mL}$ ) from Waters (Milford, USA) were used, and six carbonaceous SPE cartridges were purchased; ENVI-Carb SPE cartridge $(0.25 \mathrm{~g}, 3 \mathrm{~mL}$ and $0.5 \mathrm{~g}, 6 \mathrm{~mL})$ from Supelco (Philadelphia, USA), activated carbon $(0.5 \mathrm{~g}, 6 \mathrm{~mL}) \mathrm{from}$ Silycycle (Quebec, Canada), Carbograph SPE tubes $(0.5 \mathrm{~g}, 8 \mathrm{~mL}$ and $1 \mathrm{~g}, 15 \mathrm{~mL})$ from Chrom Tech (Minnesota, USA), and Bond Elut Carbon (0.5 g, $6 \mathrm{~mL}$ ) from Agilent (California, USA). $\mathrm{C}_{18}$ SPE (0.5 g, $\left.6 \mathrm{~mL}\right) \mathrm{was}$ from Phenomenex (California, USA). Twenty one commercial biopesticides containing S. flavescens extract were purchased from 14 Korean local companies.

\subsection{Clean-Up of Alkaloidal Matrines Using HLB SPE}

The HLB clean-up procedure as reported by Lee et al. was followed [33]. The HLB cartridge was first conditioned with $2 \mathrm{~mL} \mathrm{MeOH}$ and $2 \mathrm{~mL}$ distilled water (DW), then the sample was loaded and washed with 5\% aqueous $\mathrm{MeOH}(2 \mathrm{~mL}$ ). The cartridge was dried by vacuum, and eluted with $5 \mathrm{~mL} \mathrm{MeOH}$. The eluate was evaporated and re-dissolved with $1 \mathrm{~mL} \mathrm{MeOH}$ for UPLC analysis.

\subsection{Clean-Up of Biopesticides Containing S, flavescens Extracts Using Carbonaceous Cartridges}

In order to compare the recovery rate of matrine and oxymatrine, the six carbonaceous SPE were tested. Each cartridge was placed onto female-luer port of the SPE vacuum manifold and conditioned with $3 \mathrm{~mL} \mathrm{of} \mathrm{MeOH}$ and $3 \mathrm{~mL}$ of DW. A portion of $1 \mathrm{~mL}$ aqueous solution of matrine $\left(10 \mathrm{mg} \cdot \mathrm{L}^{-1}\right)$, oxymatrine $\left(10 \mathrm{mg} \cdot \mathrm{L}^{-1}\right)$, and the biopesticides diluted 10 times with DW, were loaded each into conditioned cartridges, respectively, and were eluted with $\mathrm{MeOH}(3 \times 3 \mathrm{~mL})$ after washing/non-washing with $12 \mathrm{~mL}$ of DW. Eluate evaporated slowly under reduced pressure, and the dried residues were re-dissolved into $1 \mathrm{~mL}$ of MeOH for analysis. UPLC system (Waters, MA, USA) with UV detector was used for matrine and oxymatrine analysis. 


\subsection{Second Clean-Up Using $\mathrm{C}_{18}$ SPE Cartridge}

ENVI-Carb SPE cartridge (0.5 g) was selected according to the result of Section 2.2. The second clean-up procedure was conducted with $\mathrm{C}_{18} \mathrm{SPE}$ cartridge $(0.5 \mathrm{~g})$ to remove unknown impurities for reduce the burden on UPLC. $\mathrm{C}_{18}$ SPE cartridge was placed to the bottom of the ENVI-Carb cartridge after DW washing as mentioned in Section 2.2. The eluate of ENVI-Carb was fully loaded to the $\mathrm{C}_{18}$ cartridge and the eluate was collected. Then the $\mathrm{C}_{18}$ cartridge was additionally eluted with $9 \mathrm{~mL}$ of $\mathrm{MeOH}$. The second clean-up efficiency was confirmed with absorbance of eluate from 210 to $800 \mathrm{~nm}$ using UV-Vis spectrophotometer (Lambda 650, Perkin-Elmer, London, UK).

\subsection{UPLC Analysis}

Matrine and oxymatrine were analyzed on a Waters UPLC system. One microliter of a sample was introduced to a Waters Acquity BEH Phenyl column (1.7 $\mu \mathrm{m}$ particle size, $3.0 \times 100 \mathrm{~mm}$, Waters, Boston, USA). The column was maintained at a temperature of $40^{\circ} \mathrm{C}$ and a constant flow rate of $0.5 \mathrm{~mL} \cdot \mathrm{min}^{-1}$. The UPLC was operated using a gradient mobile phase of solvent A (0.05\% formic acid in DW) and B (acetonitrile). The gradient was $0 \%$ 10\% B (0 - $10 \mathrm{~min}), 10 \%$ - 50\% B (10 - $15 \mathrm{~min})$, and 50\% - 100\% B (15 - $17 \mathrm{~min})$. The absorbance of matrine and oxymatrine was measured at $217 \mathrm{~nm}$.

\subsection{Method Validation}

Sample preparation and analytical methods were validated in terms of linearity, limit of quantitation (LOQ) and recovery. The linearities of the calibration curve for matrine and oxymatrine were obtained from the concentrations 1, 5, 10, 25 and $50 \mathrm{mg} \cdot \mathrm{L}^{-1}$, respectively. LOQs for matrine and oxymatrine were calculated from the concentration that produced a signal-to-noise ratio of 10 . Recoveries of matrine and oxymatrine were tested by spiking the standard material at a concentration of $10 \mathrm{mg} \cdot \mathrm{L}^{-1}$ in the extract of neem and its biopesticide that were not containing the analytes. The precision of the method was expressed in percentage (\%) of relative standard deviation (RSD).

\section{Results and Discussion}

\subsection{Application of HLB SPE for the Matrines}

Recently, Lee et al. reported the analytical method using HLB SPE and UPLC for the quantitative analysis of bioactive limonoids in the biopesticides containing neem extract [33]. First, the HLB clean-up method was applied to the purification method for quantitation of alkaloidal matrines, which were spiked at a concentration of $10 \mathrm{mg} \cdot \mathrm{L}^{-1}$ in the biopesticide containing neem extract. However, the recovery was below $60 \%$ on the standard spiked water sample. To find the reason for the low recovery on HLB experiment, the partition coefficients (log P) were compared with azadirachtin which was an indicator of neem extract, matrine, and oxymatrine. The values were calculated from ALOGPS v2.1 that was provided by the Virtual Computational Chemistry Laboratory [34]. The calculated $\log \mathrm{P}$ values of azadirachtin, matrine and oxymatrine were $1.53,1.44$, and -0.33 , respectively. However, matrine which has tertiary amine could be easily protonated and present as charged amine form in water solution due to its pKa [35]. Therefore, the $\log \mathrm{P}$ would be compared with the protonated matrine, and it was calculated to -1.37 from ALOGPS. These values of oxymatrine and protonated matrine were lower by about 70 and 800 times, respectively, than that of azadirachtin. Therefore, the HLB SPE method would not be suitable for the purification of alkaloidal matrines on the mixture of $S$. flavescens.

Furthermore, the LC condition had to be optimized to get the best result particularly on good sensitivity for matrine and oxymatrine. Acquity UPLC BEH Phenyl column has been known to provide complementary selectivity to $\mathrm{C}_{18}$ stationary phase, especially for aromatic compounds. However, $\mathrm{C}_{18}$ column was used for HPLC analysis of matrine and oxymatrine in previous studies [29]. Acquity UPLC BEH Phenyl and $\mathrm{C}_{18}$ column were tested to compare the sensitivity of matrine and oxymatrine. The sensitivity of BEH phenyl column was a little better than that of $\mathrm{C}_{18}$ column. The optimized analytical condition was achieved using a mobile phase consisting of $0.05 \%$ formic acid and acetonitrile on an Acquity UPLC BEH Phenyl column. Figure 1 presents the chromatogram of matrine and oxymatrine in biopesticide sample. The retention times of both materials under analysis condition from Section 2.4 were 5.75 and 6.84 min, respectively. 


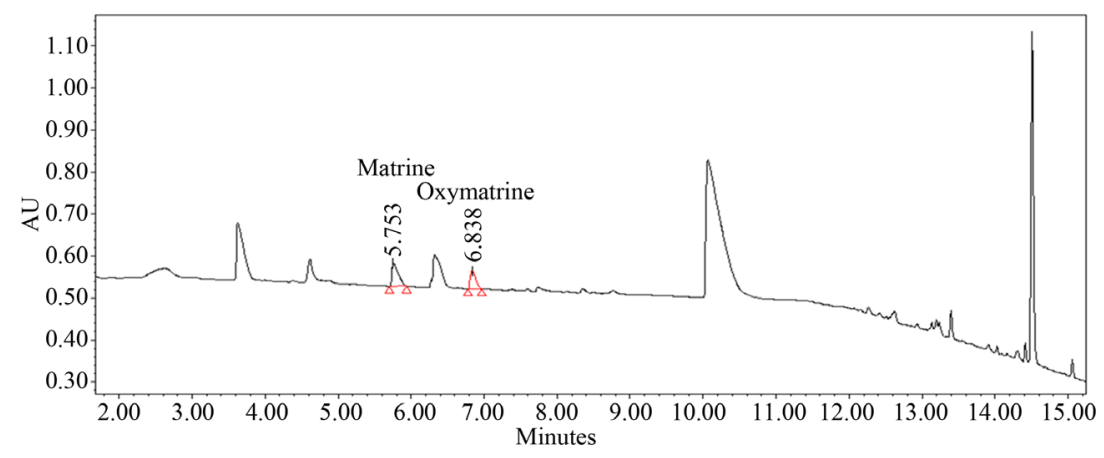

Figure 1. UPLC chromatogram of matrine and oxymatrine in biopesticide.

\subsection{Comparison of Carbonaceous Cartridges Efficiency}

This study tried to find out the suitable SPE for the clean-up of biopesticides containing S. flavescens extract and various supplementary materials, and selected carbonaceous SPE. Carbonaceous SPE can be applied to the aqueous sample unlikely to silica gel or Florisil cartridge. Also, many reports have described the extraction of polar analytes and/or multi-residue extractions such as chloroaniline, chlorophenols, and polar pesticides with graphitized carbons [36]-[39]. The optimum dilution of sample was considered due to the viscosity and crudity of S. flavescens extract and its biopesticides. The dilution rate was applied from 1 to 100 folds with DW in this experiment, and the diluted samples were applied to carbonaceous SPE for the purification of matrines from $S$. flavescens extract and its biopesticides.

Six carbonaceous cartridges were tested to compare the recovery rate of matrine and oxymatrine with or without washing step. The recoveries of matrine and oxymatrine both with and without DW washing were $78.6 \%$ $131.0 \%$ in ENVI-Carb (0.25 and $0.5 \mathrm{~g}$ ) and Bond Elut Carbon tube ( $0.5 \mathrm{~g})$, whereas below $48 \%$ in the other SPE cartridge (Figure 2). When the purification efficiency was compared with the absorbance at $217 \mathrm{~nm}$ on the eluate from ENVI-Carb SPE cartridge, the disturbance was reduced by around $25 \%$ after washing with $12 \mathrm{~mL}$ DW without recovery changes (Figure 3). In order to find out the optimal dilution rate of biopesticide, the samples were diluted $1,10,20,50$, and 100 times with DW and investigated for the recoveries of matrine and oxymatrine after ENVI-Carb clean-up. The recoveries of matrine and oxymatrine of biopesticide without dilution were $68.0 \%$ and $73.0 \%$, respectively, but the recoveries of $10,20,50$, and 100 times diluted samples ranged from $96.3 \%$ - 106.5\% (data not shown). Finally, ENVI-Carb $0.5 \mathrm{~g}$ and dilution rate of 10 times were selected for the clean-up method which showed the best recovery of both matrine and oxymatrine. However, the color of ENVI-Carb eluate of biopesticides was still evident, hence, second purification was considered to diminish the impurities and to reduce the column damages on the instrument.

\subsection{Second Clean-Up Efficiency of $\mathrm{C}_{18}$ SPE Cartridge}

To improve data reproducibility, the second purification step was taken into consideration, and $\mathrm{C}_{18}$ SPE was adopted to remove non-polar impurities. The $\mathrm{C}_{18}$ SPE and ENVI-Carb SPE were connected sequentially after washing step of the method 2.3, and $\mathrm{MeOH}$ and acetonitrile were tested as elution solvents to find the suitable one because the two solvents were shown to have the good recoveries above 95\%. The ENVI-Carb and $\mathrm{C}_{18} \mathrm{SPE}$ were eluted with $3 \times 3 \mathrm{~mL} \mathrm{MeOH}$ or acetonitrile, then $9 \mathrm{~mL} \mathrm{MeOH}$ or acetonitrile was additionally eluted to $\mathrm{C}_{18}$ SPE cartridge. The spectra for the eluates of two solvents were measured with UV-visible spectrophotometer, and $\mathrm{MeOH}$ showed better impurity removing efficiency than acetonitrile on the comparison of $\mathrm{Abs}_{217}$ (Figure 3). And finally, $\mathrm{MeOH}$ was accepted as an elution solvent for the SPE clean-up. Second clean-up efficiency by $\mathrm{C}_{18}$ SPE cartridge is presented in Figure 3. The greatest decrease of impurities was shown in clean-up with the combination of ENVI-Carb and $\mathrm{C}_{18}$ SPE including DW washing, and there was no adverse effect to the recovery. Therefore, these results suggest that the clean-up method was accepted for matrine and oxymatrine analysis in biopesticides containing $S$. flavescens extract (Figure 4).

\subsection{Method Validation}

Table 1 presents linearity, LOQ, and recovery of matrine and oxymatrine for the validation study. Linear corre- 


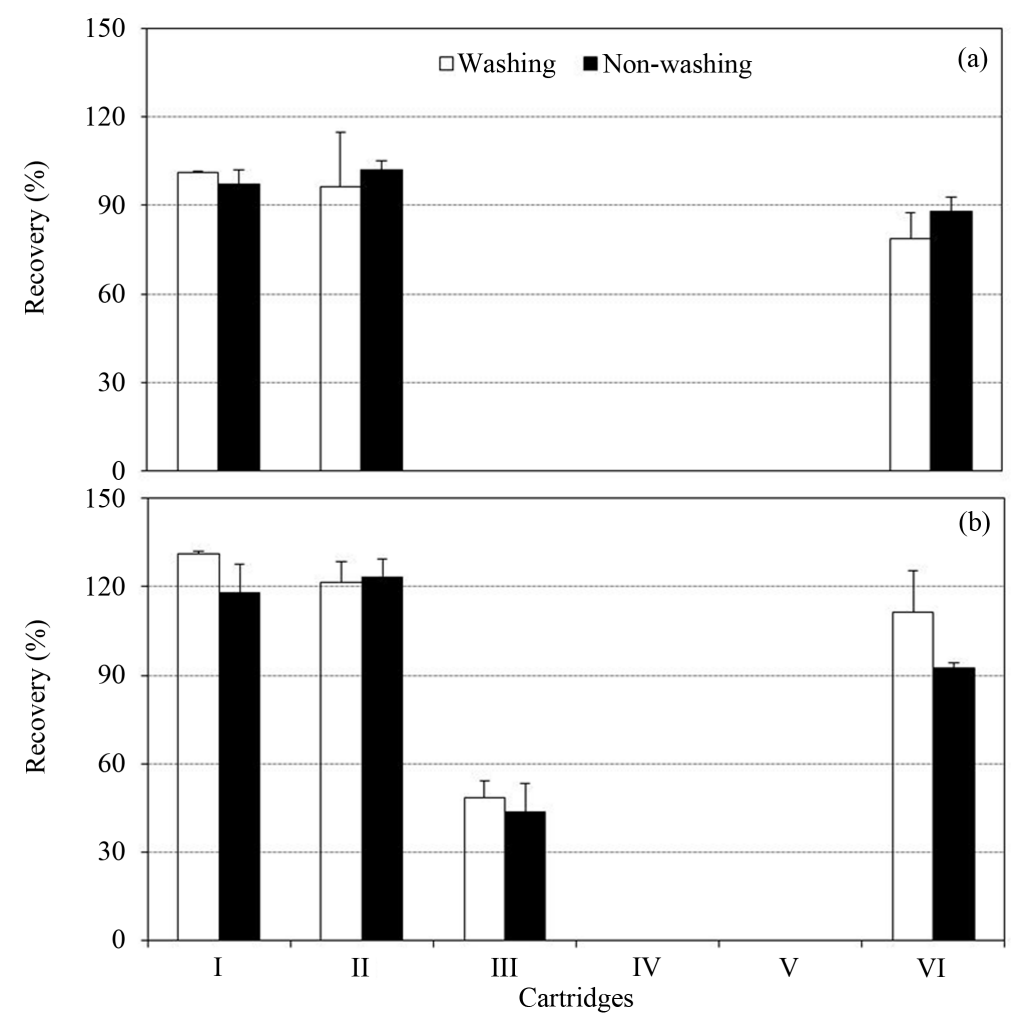

Figure 2. Recoveries of matrine (a) and oxymatrine (b) in the selected six cartridges with and without DW washing (I: ENVI-Carb 0.25 g, II: ENVI-Carb 0.5 g, III: Activated Carbon 0.5 g, IV: Carbograph 0.5 g, V: Carbograph 1 g, VI: Bond Elut $0.5 \mathrm{~g})$. Vertical bars represent $\pm \mathrm{SD}$ of the means.

Table 1. Method validation result for matrine and oxymatrine.

\begin{tabular}{cccccc}
\hline Materials & $\begin{array}{c}\text { Linearity } \\
\left(\mathrm{r}^{2}\right)\end{array}$ & $\begin{array}{c}\text { Recovery } \\
(\%)\end{array}$ & $\begin{array}{c}\text { LOQ } \\
\left(\mathrm{mg} \cdot \mathrm{L}^{-1}\right)\end{array}$ & Inter-day & Intra-day \\
\hline Matrine & 0.9986 & $105.0 \pm 1.39^{\dagger}$ & 0.266 & 5.1 & 2.9 \\
Oxymatrine & 0.9996 & $103.6 \pm 2.05$ & 0.684 & 5.9 & 4.2 \\
\hline
\end{tabular}

${ }^{\dagger}$ The data represent the mean values $\pm \mathrm{SD}$ of three replicates.

lations from 1 to $50 \mathrm{mg} \cdot \mathrm{L}^{-1}$ for both matrine and oxymatrine were detected with coefficient correlations of 0.9986 and 0.9996 , respectively. The method LOQs of matrine and oxymatrine were 0.226 and $0.684 \mathrm{mg} \cdot \mathrm{L}^{-1}$, respectively. Validation of the analytical method was conducted in terms of recovery of the spiked sample that did not contain $S$. flavescens. Recoveries of $10 \mathrm{mg} \cdot \mathrm{L}^{-1}$ matrine and oxymatrine were found to be 105.0 and $103.6 \%$ using the established method. The inter- and intra-day precision of the method were determined from recovery of both materials on three separate days. The method was reliable since the RSD percentage (2.9\% - 5.9\%) below 15, which was the normal percent value. These results suggest that the experimental procedure including clean-up and instrumental analysis was suitable for use in the analysis of targeted materials in biopesticide samples.

\subsection{Matrine and Oxymatrine Levels in Commercial Biopesticides Containing S. flavescens Extract}

The developed method for matrine and oxymatrine analysis was applied to the extract of S. flavescens and its biopesticides. Matrine and oxymatrine in all samples were detected at $0.00-0.66$ and $<$ LOQ-0.16\%, respectively (Table 2). Recently, Yang and Zhao [18] and Mao and Henderson [20] reported the antifungal and insecticidal activities of matrines as $\mathrm{EC}_{50}$ and $\mathrm{LD}_{50}$ values; the values were $26-1133 \mathrm{mg} \cdot \mathrm{L}^{-1}$ and $10.1-13.3 \mu \mathrm{g}$ 

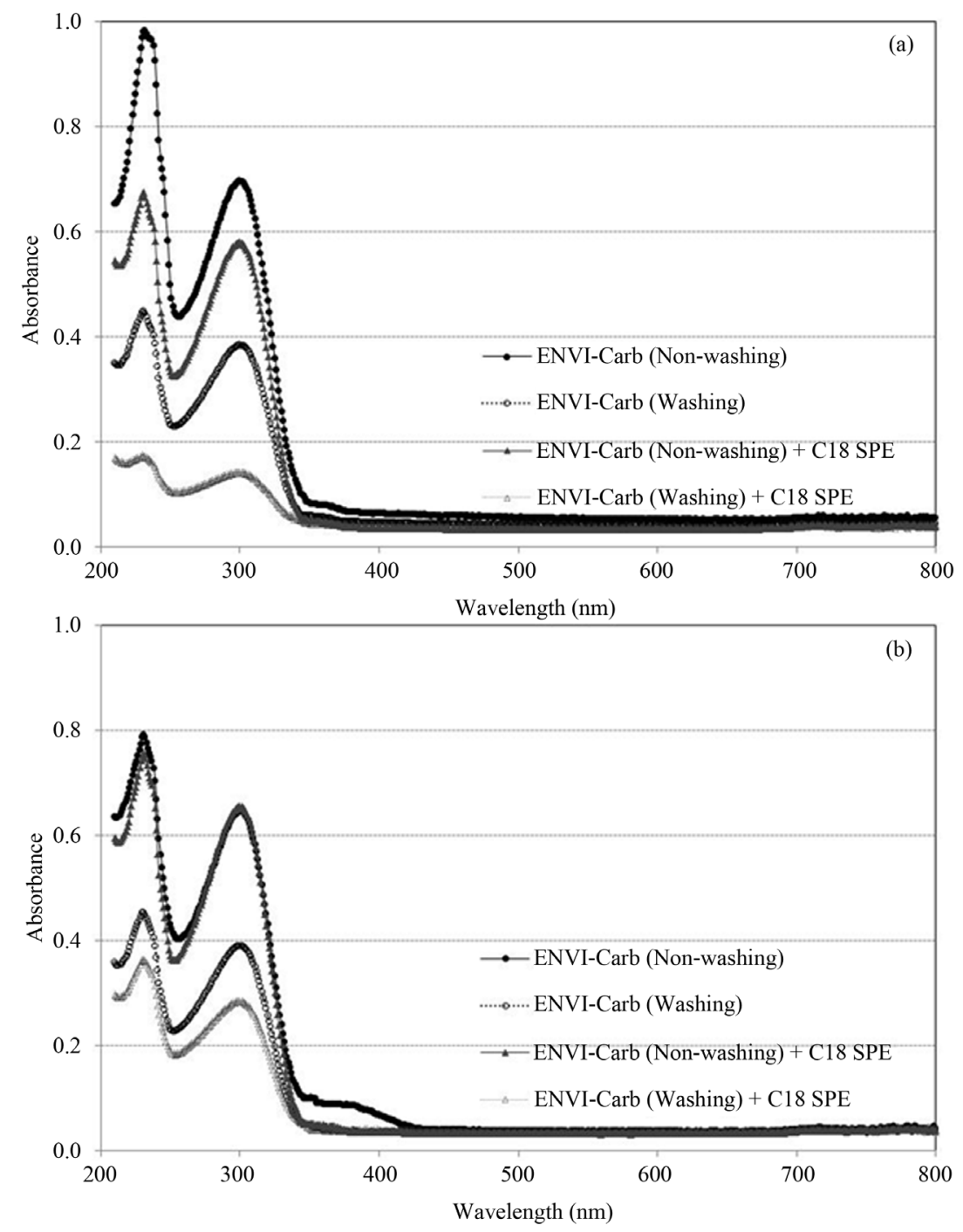

Figure 3. UV-Vis spectra of $\mathrm{MeOH}$ (a) and acetonitrile (b) eluate of biopesticide sample with and without $\mathrm{C}_{18}$ SPE cartridge clean-up.

per insect, respectively. If we only consider the concentration of alkaloidal matrines as bioactive materials, the contents of matrine and oxymatrine in some products among the tested biopesticides were assumed to be sufficient as crop protection agents. However, if we consider the practical use guideline of biopesticide, the concentration of the active ingredient would be expected to be lower than $\mathrm{EC}_{50}$ and $\mathrm{LD}_{50}$ level, because the general guideline for field application was suggested be 100 - 1000 folds diluted with water. In a survey of matrines present in biopesticides from $S$. flavescens, the concentration of bioactive materials showed wide ranges and these results would be related to the crop protection efficiency. Thus, the quality control of the commercial biopesticide should be performed.

\section{Conclusion}

This study successfully developed and validated the clean-up method by using carbonaceous and $\mathrm{C}_{18}$ SPE cartridge for the simultaneous determination of matrine and oxymatrine in biopesticides containing $S$. flavescens extract. This is the first report of the simultaneous analysis of matrine and oxymatrine in biopesticides which are constituted with various interferences of instrumental analysis such as pigments, lipids, and surfactants. This method could be contributed to the manufacture for quality control and to the method development for the quantitative analysis or effective purification of alkaloidal indicator in other biopesticides. 

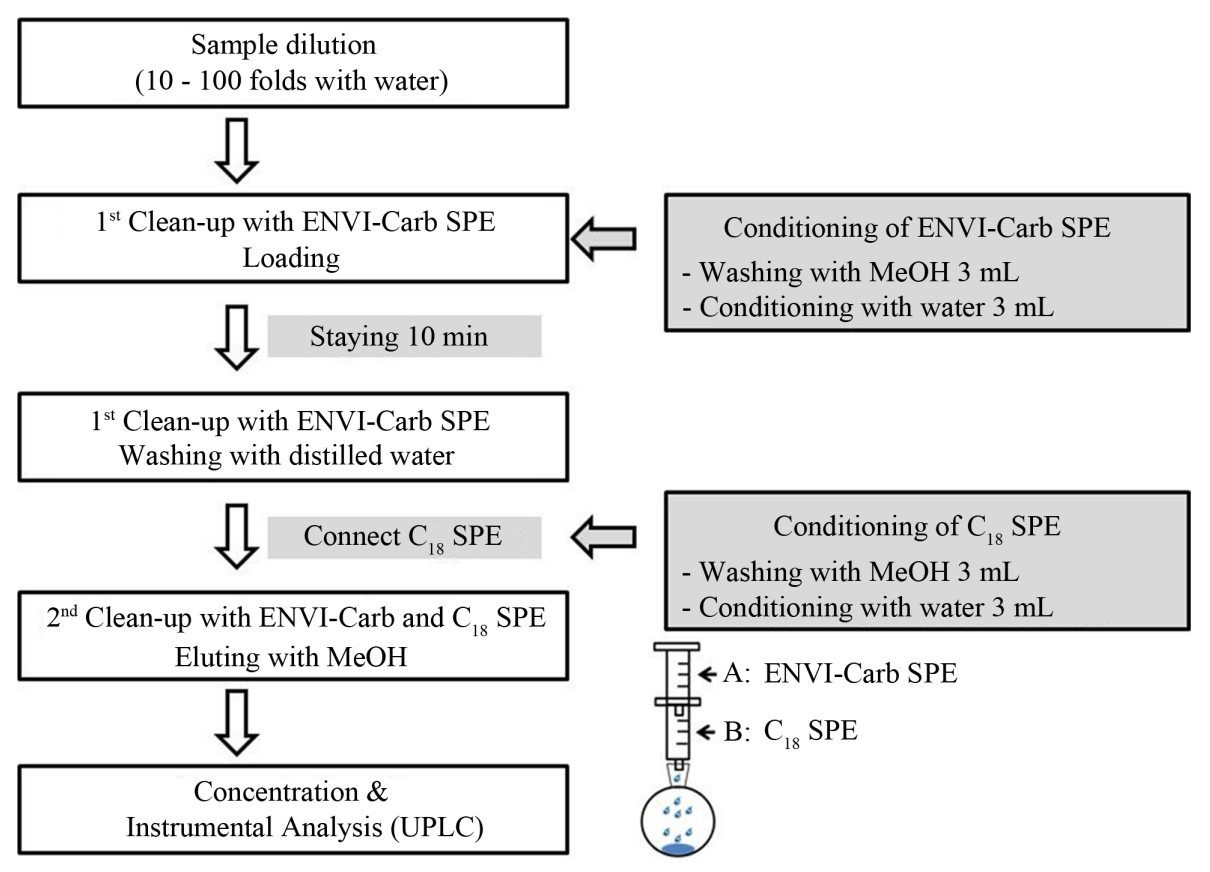

Figure 4. Flow chart for matrine and oxymatrine analyses in biopesticides.

Table 2. Matrine and oxymatrine content in S. flavescens extract and its biopesticides.

\begin{tabular}{|c|c|c|c|}
\hline Samples & Matrine (\%) & Oxymatrine (\%) & Total (\%) \\
\hline S. flavescens extract & 0.31 & $<\mathrm{LOQ}$ & 0.31 \\
\hline 1 & 0.37 & 0.10 & 0.47 \\
\hline 2 & 0.15 & $<\mathrm{LOQ}$ & 0.15 \\
\hline 3 & 0.00 & 0.00 & 0.00 \\
\hline 4 & 0.01 & $<\mathrm{LOQ}$ & 0.01 \\
\hline 5 & 0.00 & $<\mathrm{LOQ}$ & 0.00 \\
\hline 6 & 0.27 & 0.05 & 0.32 \\
\hline 7 & 0.23 & $<$ LOQ & 0.23 \\
\hline 8 & 0.59 & $<\mathrm{LOQ}$ & 0.59 \\
\hline 9 & 0.18 & $<\mathrm{LOQ}$ & 0.18 \\
\hline 10 & 0.12 & 0.16 & 0.28 \\
\hline 11 & 0.16 & $<\mathrm{LOQ}$ & 0.16 \\
\hline 12 & 0.24 & $<\mathrm{LOQ}$ & 0.24 \\
\hline 13 & 0.05 & 0.14 & 0.19 \\
\hline 14 & 0.35 & $<\mathrm{LOQ}$ & 0.35 \\
\hline 15 & 0.45 & $<\mathrm{LOQ}$ & 0.45 \\
\hline 16 & 0.66 & 0.05 & 0.71 \\
\hline 17 & 0.35 & 0.12 & 0.47 \\
\hline 18 & 0.01 & $<\mathrm{LOQ}$ & 0.01 \\
\hline 19 & 0.14 & $<\mathrm{LOQ}$ & 0.14 \\
\hline 20 & 0.32 & $<\mathrm{LOQ}$ & 0.32 \\
\hline 21 & 0.23 & 0.12 & 0.35 \\
\hline
\end{tabular}




\section{Acknowledgements}

This study was carried out with the support of "Cooperative Research Program for Agricultural Science \& Technology Development (PJ009219)”, Rural Development Administration and "Research Program for Agricultural Science \& Technology Development (PJ008468)" and "Postdoctoral Fellowship Program of Chemical Safety Division”, National Academy of Agricultural Science, Rural Development Administration, Republic of Korea.

\section{References}

[1] Kim, J.H. and Smith, A. (2001) Distribution of Organochlorine Pesticides in Soils from South Korea. Chemosphere, 43, 137-140. http://dx.doi.org/10.1016/S0045-6535(00)00281-2

[2] Cerejeira, M.J., Viana, P., Batista, S., Pereira, T., Silva, E., Valerio, M.J., Silva, A., Ferreira, M. and Silva-Fernandes, A.M. (2003) Pesticides in Portuguese Surface and Ground Waters. Water Research, 37, 1055-1063. http://dx.doi.org/10.1016/S0043-1354(01)00462-6

[3] Katsumata, H., Fujii, A., Kaneco, S., Suzuki, T. and Ohta, K. (2005) Determination of Simazine in Water Samples by HPLC after Preconcentration with Diatomaceous Earth. Talanta, 65, 129-134.

[4] Tripathi, G., Kachhwaha, N. and Dabi, I. (2009) Impact of Phorate on Malate Dehydrogenases, Lactate Dehydrogenase and Proteins of Epigeic, Anecic and Endogeic Earthworms. Pesticide Biochemistry and Physiology, 95, 100-105. http://dx.doi.org/10.1016/j.pestbp.2009.07.004

[5] Arnason, J.T., Philogene, B.J.R., Morand, P., Imrie, L., Iyengar, S., Duval, F., Soucy-Breau, C., Scaiano, J.V., Werstiuk, N.H., Hasspieler, B. and Downe, A.E.R. (1989) Insecticides of Plant Origin. In: Arnason, J.T., Philogene, B.J.R. and Morand, P., Eds., ACS Symposium Series No. 387, American Chemical Society, Washington DC, 164-172. http://dx.doi.org/10.1021/bk-1989-0387.ch012

[6] Wink, M. (1993) Production and Application of Phytochemicals from an agricultural perspective. In: Beek, V.T.A. and Breteler, H., Eds., Phytochemistry and Agriculture Clarendon, Oxford, Vol. 34, 171-213.

[7] Chen, C., Guo, S.M. and Liu, B. (2000) A Randomized Controlled Trial of Kurorinone versus Interferon- $\alpha 2 a$ Treatment in Patients with Chronic Hepatitis B. Journal of Viral Hepatitis, 7, 225-229. http://dx.doi.org/10.1046/j.1365-2893.2000.00216.x

[8] Ma, L., Wen, S., Zhan, Y., He, Y., Liu, X. and Jiang, J. (2008) Anticancer Effects of the Chinese Medicine Matrine on Murine Hepatocellular Carcinoma Cells. Planta Medica, 74, 245-251. http://dx.doi.org/10.1055/s-2008-1034304

[9] Jin, J.H., Kim, J.S., Kang, S.S., Son, K.H., Chang, H.W. and Kim, H.P. (2010) Anti-Inflammatory and Anti-Arthritic Activity of Total Flavonoids of the Root of Sophora flavescens. Journal of Ethnopharmacology, 127, 589-595. http://dx.doi.org/10.1016/j.jep.2009.12.020

[10] Wu, L., Miyase, T., Ueno, A., Kuroyanagi, M., Noro, T. and Fukushima, S. (1985) Studies on the Constituents of Sophora flavescens AITON II. Chemical and Pharmaceutical Bulletin, 33, 3231-3236. http://dx.doi.org/10.1248/cpb.33.3231

[11] Yagi, A., Fukunaga, N., Okuzako, N., Mifuchi, I. and Kawamoto, F. (1989) Antifungal Substances from Sophora favescens. Shoyakugaku Zasshi, 43, 343-347.

[12] Tang, W. and Eisenbrand, G. (1992) Chemistry, Pharmacology, and Use in Traditional and Modern Medicine. SpringerVerlag, Berlin, 931-943.

[13] Ryu, S.Y., Lee, H.S., Kim, Y.K. and Kim, S.H. (1997) Determination of Isoprenyl and Lavandulyl Positions of Flavonoids from Sophora flavescens by NMR Experiment. Archives of Pharmacal Research, 20, 491-495. http://dx.doi.org/10.1007/BF02973946

[14] Woo, E.R., Kwak, J.H., Kim, H.J. and Park, H.K. (1998) A New Prenylated Flavonol from the Roots of Sophora flavescens. Journal of Natural Products, 61, 1552-1554. http://dx.doi.org/10.1021/np980103j

[15] Lee, G.S., Kim, E.S., Cho, S.I., Kim, J.H., Choi, G., Ju, Y.S., Park, S.H., Jeong, S.I. and Kim, H.J. (2010) Antibacterial and Synergistic Activity of Prenylated Chalcone Isolated from the Roots of Sophora flavescens. Journal of the Korean Society for Applied Biological Chemistry, 53, 290-296. http://dx.doi.org/10.3839/jksabc.2010.045

[16] Zheng, Y.Q., Yao, J.R. and Shao, X.D. (2000) Review on the Constituents and Agricultural Application of Sophora flavescens Ait. Pesticide Science Administration, 21, 24-26.

[17] Sohn, H.Y., Son, K.H., Kwon, C.S., Kwon, G.S. and Kang, S.S. (2004) Antimicrobial and Cytotoxic Activity of 18 Prenylated Flavonoids Isolated from Medicinal Plants: Morus alba L., Morus mongolica Schneider, Broussnetia papyrifera (L.) Vent, Sophora flavescens Ait and Echinosophora koreensis Nakai. Phytomedicine, 11, 666-672. http://dx.doi.org/10.1016/j.phymed.2003.09.005 
[18] Yang, X.Y. and Zhao, B.G. (2006) Antifungal Activities of Matrine and Oxymatrine and Their Synergetic Effects with Chlorothalonil. Journal of Forestry Research, 17, 323-325. http://dx.doi.org/10.1007/s11676-006-0074-5

[19] Liu, Z.L., Goh, S.H. and Ho, S.H. (2007) Screening of Chinese Medicinal Herbs for Bioactivity against Sitophilus zeamais Motschulsky and Tribolium castaneum (Herbst). Journal of Stored Products Research, 43, 290-296. http://dx.doi.org/10.1016/j.jspr.2006.06.010

[20] Mao, L. and Henderson, G. (2007) Antifeedant Activity and Acute Residual Toxicity of Alkaloids from Sophora flavescens (Leguminosae) against Formosan Subterranean Termites (Isoptera: Rhinotermitidae). Journal of Economic Entomology, 100, 866-870. http://dx.doi.org/10.1603/0022-0493(2007)100[866:AAAAAR]2.0.CO;2

[21] Ruiz-Gutiérrez, V. and Pérez-Camino, M.C. (2000) Update on Solid-Phase Extraction for the Analysis of Lipid Classes and Related Compounds. Journal of Chromatography A, 885, 321-341. http://dx.doi.org/10.1016/S0021-9673(00)00181-3

[22] Pasquet, V., Chérouvrier, J.R., Farhat, F., Thiéry, V., Piot, J.M., Bérard, J.B., Kaas, R., Serive, B., Patrice, T., Cadoret, J.P. and Picot, L. (2011) Study on the Microbial Pigments Extraction Process: Performance of Microwave Assisted Extraction. Process Biochemistry, 46, 59-67. http://dx.doi.org/10.1016/j.procbio.2010.07.009

[23] Yang, W.H., Wang, J.H., Li, X.L. and Du, Z.X. (2011) A New Method Research for Determination of Natural Pigment Crocin Yellow in Foods by Solid-Phase Extraction Ultrahigh Pressure Liquid Chromatography. Journal of Chromatography A, 1218, 1423-1428. http://dx.doi.org/10.1016/j.chroma.2010.12.121

[24] Zhang, Y., Yin, C., Kong, L. and Jiang, D. (2011) Extraction Optimization, Purification and Major Antioxidant Component of Red Pigments Extracted from Camellia japonica. Food Chemistry, 129, 660-664. http://dx.doi.org/10.1016/j.foodchem.2011.05.001

[25] Housaindokht, M.R. and Pour, A.N. (2012) Study the Effect of HLB of Surfactant on Particle Size Distribution of Hematite Nanoparticles Prepared via the Reverse Microemulsion. Solid State Sciences, 14, 622-625.

http://dx.doi.org/10.1016/j.solidstatesciences.2012.01.016

[26] Ribble-Garlick, E.J., Henry, R.A. and Swltalski, L.J. (1997) Utilizing Short Cartridge Columns for Fast HPLC Analyses: Optimization of a Fast Nicotine Assay. American Laboratory, 29, 24-26.

[27] Taguchi, S., Yoshida, S., Tanaka, Y. and Hori, S. (2001) Simple and Rapid Analysis of Trenbolone and Zeranol Residues in Cattle Muscle and Liver by Stack-Cartridge Solid-Phase Extraction and HPLC Using on-Line Clean-Up with EC and UV Detection. Journal of the Food Hygienic Society of Japan, 42, 226-230. http://dx.doi.org/10.3358/shokueishi.42.226

[28] Wong, S., Tsui, S. and Kwan, S. (2002) Analysis of Proprietary Chinese Medicines for the Presence of Toxic Ingredients by LC/MS/MS. Journal of Pharmaceutical and Biomedical Analysis, 30, 161-170. http://dx.doi.org/10.1016/S0731-7085(02)00172-3

[29] Li, K. and Wang, H.J. (2004) Simultaneous Determination of Matrine, Sophoridine and Oxymatrine in Sophora flavescens Ait. By High Performance Liquid Chromatography. Biomedical Chromatography, 18, 178-182. http://dx.doi.org/10.1002/bmc.308

[30] Jong, T.T., Lee, M.R., Chiang, Y.C. and Chiang, S.T. (2006) Using LC/MS/MS to Determine Matrine, Oxymatrine, Ferulic Acid, Mangiferin, and Glycyrrhizin in the Chinese Medicinal Preparations Shiau-feng-saan and Dang-gueinian-tong-tang. Journal of Pharmaceutical and Biomedical Analysis, 40, 472-477. http://dx.doi.org/10.1016/j.jpba.2005.07.036

[31] Zhou, Q.X., Xie, G.H., Xiao, J.P. and Wang, W.D. (2008) Sensitive Determination of Fenpropathrin, Cyhalothrin and Deltamethrin in Environmental Water Samples Using Multiwalled Carbon Nanotubes Cartridge Prior to HPLC. Chinese Chemical Letters, 19, 95-98. http://dx.doi.org/10.1016/j.cclet.2007.10.044

[32] Yang, Z., Gao, S., Yin, T., Kulkarni, K.H., Teng, Y., You, M. and Hu, M. (2010) Biopharmaceutical and Pharmacokinetic Characterization of Matrine as Determined by a Sensitive and Robust UPLC-MS/MS Method. Journal of Pharmaceutical and Biomedical Analysis, 51, 1120-1127. http://dx.doi.org/10.1016/j.jpba.2009.11.020

[33] Lee, J.W., Jin, C.L., Jang, K.C., Choi, G.H., Lee, H.D. and Kim, J.H. (2013) Investigation on the Insecticidal Limonoid Content of Commercial Biopesticides and Neem Extract Using Solid Phase Extraction. Journal of Agricultural Chemistry and Environment, 2, 81-85. http://dx.doi.org/10.4236/jacen.2013.24012

[34] ALOGPS (2013) Munich, Germany: Virtual Computational Chemistry Laboratory. http://www.vcclab.org.

[35] Chen, Z.F., Mao, L., Liu, L.M., Liu, Y.C., Peng, Y., Hong, X., Wang, H.H., Liu, H.G. and Liang, H. (2011) Potential New Inorganic Antitumour Agents from Combining the Anticancer Traditional Chinese Medicine (TCM) Matrine with Ga(III), Au(III), Sn(IV) Ions, and DNA Binding Studies. Journal of Inorganic Biochemistry, 105, 171-180. http://dx.doi.org/10.1016/j.jinorgbio.2010.10.007

[36] Di Corcia, A. and Samperi, R. (1990) Determination of Chloroaniline Traces in Environmental Waters by Selective Extraction with Two Traps in Tandem and Liquid Chromatography. Analytical Chemistry, 62, 1490-1494. 
[37] Di Corcia, A., Samperi, R., Marcomini, A. and Stelluto, S. (1993) Graphitized Carbon Black Extraction Cartridges for Monitoring Polar Pesticides in Water. Analytical Chemistry, 65, 907-912. http://dx.doi.org/10.1021/ac00055a013

[38] Crescenzi, C., Di Corcia, A., Marcomini, A. and Samperi, R. (1997) Detection of Poly(Ethylene Glycols) and Related Acidic Forms in Environmental Waters by Liquid Chromatography/Electrospray/Mass Spectrometry. Environmental Science and Technology, 31, 2679-2685. http://dx.doi.org/10.1021/es9700966

[39] Rodriguez, I., Mejuto, M.C., Bollain, R. and Cela, J. (1997) Evaluation of Two Solid-Phase Extraction Procedures for the Preconcentration of Chlorophenols in Drinking Water. Journal of Chromatography A, 786, 285-292. http://dx.doi.org/10.1016/S0021-9673(97)00579-7 